Masashi Niimi • Takeshi Ogawara • Tatsuya Yamashita

Yasuchika Yamamoto • Atsunori Ueyama

Toshimi Kambe • Takashi Okamoto • Takashi Ban

Hidenori Tamanoi · Kouichi Ozaki · Tsutomu Fujiwara

Hiroyuki Fukui • Ei-ichi Takahashi · Hiroyuki Kyushiki

Akira Tanigami

\title{
Identification of GFAT1-L, a novel splice variant of human glutamine: fructose-6-phosphate amidotransferase (GFAT1) that is expressed abundantly in skeletal muscle
}

Received: May 30, 2001 / Accepted: July 2, 2001

\begin{abstract}
Glutamine:fructose-6-phosphate amidotransferase (GFAT1) is the rate-limiting enzyme in the hexosamine biosynthetic pathway, which plays an important role in hyperglycemia-induced insulin resistance. To evaluate the role of GFAT1 expression, we analyzed the expression profiles of GFAT1 mRNA in various human tissues using reverse transcriptase-polymerase chain reaction. We report here the identification and cDNA cloning of a novel GFAT1 splice variant expressed abundantly in skeletal muscle and heart. This subtype, designated GFAT1-L, contains a 54-bp insertion within the GFAT1 coding sequence. Recombinant GFAT1-L protein possessed functional GFAT activities and biochemical characteristics similar to GFAT1. Previously, GFAT1 was considered a simplex enzyme. The identification of a novel GFAT1 subtype possessing functional enzymatic activity and tissue-specific expression should provide additional insight into the mechanism of skeletal muscle insulin resistance and diabetes complications.
\end{abstract}

Key words GFAT1 $\cdot$ NIDDM $\cdot$ Insulin resistance $\cdot$ Skeletal muscle $\cdot$ Tissue-specific gene

M. Niimi · T. Ogawara $\cdot$ T. Ban $\cdot$ H. Tamanoi $\cdot$ K. Ozaki T. Fujiwara $\cdot$ E. Takahashi $\cdot$ H. Kyushiki $\cdot$ A. Tanigami $(\varangle)$ Otsuka GEN Research Institute, Otsuka Pharmaceutical Co., Ltd., 463-10 Kagasuno, Kawauchi-cho, Tokushima 771-0192, Japan Tel. +81-88-665-2888; Fax +81-88-637-1035

e-mail: atanigam@otsuka.gr.jp

T. Yamashita $\cdot$ Y. Yamamoto $\cdot$ A. Ueyama $\cdot$ T. Kambe

First Institute of New Drug Research, Otsuka Pharmaceutical Co., Ltd., Tokushima, Japan

T. Okamoto

Ako Research Institute, Otsuka Pharmaceutical Co., Ltd., Hyogo,

Japan

M. Niimi $\cdot$ T. Okamoto $\cdot$ H. Fukui

Department of Pharmacology, Faculty of Pharmaceutical Sciences,

The University of Tokushima, Tokushima, Japan

\section{Introduction}

Insulin resistance, leading to chronic hyperglycemia, is a cardinal feature of noninsulin-dependent diabetes mellitus (NIDDM) (Rizza et al. 1981). Recent studies have shown that increased activity of the hexosamine biosynthetic pathway might contribute to glucose-induced insulin resistance in skeletal muscle (DeFronzo et al. 1985; Garvey et al. 1987; Rossetti et al. 1990; Marshall et al. 1991; Baron et al. 1995; Robinson et al. 1995; Davidson et al. 1994; Virkamaki et al. 1997), which is a major organ of insulin resistance in NIDDM patients. Specifically, glutamine:fructose-6phosphate amidotransferase (GFAT1), a key regulator and rate-limiting enzyme in the formation of hexosamine products (Crook et al. 1995; McClain et al. 1996; Daniels et al. 1996; Chen et al. 1997), displays elevated activity in the skeletal muscle of NIDDM patients (Yki-Jarvinen et al. 1996) and in $o b / o b$ mice, a rodent model of NIDDM (Buse et al. 1997). Transgenic mice overexpressing the GFAT1 gene in skeletal muscle and adipose tissue also exhibit insulin resistance, as determined by the hyperinsulinemic euglycemic glucose clump technique (Herbert et al. 1996; Cooksey et al. 1999). On the other hand, in situ hybridization and immunostaining studies show that GFAT1 expression is normally tightly regulated in both a tissue-specific and a cell-specific manner (Nerlich et al. 1998; Yki-Jarvinen et al. 1999). The recent identification of GFAT2, a highly similar gene that exhibits different tissue distribution from GFAT1, suggests additional levels of complexity in GFAT activity (Oki et al. 1999).

Through examination of GFAT1 mRNA expression profiles, we have identified an additional GFAT1 variant expressed predominantly in skeletal muscle. We present here the cloning and biochemical characterization of a novel splice variant of GFAT1, designated GFAT1-L. 


\section{Materials and methods}

\section{Expression profile of GFAT1 mRNA}

Expression profile of GFAT1 mRNA was analyzed by polymerase chain reaction (PCR) amplification from commercially prepared human tissue cDNA libraries (QUICKClone human heart, brain, kidney, skeletal muscle, pancreas, liver, small intestine, and fat libraries; Clontech, Palo Alto, CA, USA) with GFAT1-specific primers (AGC CCTCTGTTGATTGGTGT and TCCATCTGGAGTGT TTGCAC). Amplification was performed using KOD dash polymerase (TOYOBO, Tokyo, Japan) under the following conditions: 40 cycles of $95^{\circ} \mathrm{C}$ for $30 \mathrm{~s}, 55^{\circ} \mathrm{C}$ for $30 \mathrm{~s}$, and $72^{\circ} \mathrm{C}$ for $45 \mathrm{~s}$, with a final extension at $72^{\circ} \mathrm{C}$ for $1 \mathrm{~min}$. PCR products were analyzed by electrophoresis through a $4 \%$ agarose gel.

\section{Quantitative PCR analysis}

Quantitative PCR analysis specific for the GFAT1-L gene was carried out using SYBR Green I methods (Wittwer et al. 1997; Morrison et al. 1998; Hiratsuka et al. 1999) and an ABI PRISM 7700 sequence detector (Perkin-Elmer Applied Biosystems, Foster City, CA, USA). Amplification mixes contained template DNA (described earlier), 10× SYBR Green PCR buffer (Perkin-Elmer Applied Biosystems), $200 \mu \mathrm{M}$ dNTPs, $5 \mathrm{mM} \mathrm{MgCl}_{2}, 1.25$ units of AmpliTaq Gold (Perkin-Elmer Applied Biosystems) and $5 \mathrm{pM}$ of each primer (AGCTAGGACTCAGATTGGATC and TCCATCTGGAGTGTTTGCAC). The amplification was carried out for 50 cycles under the following conditions: $95^{\circ} \mathrm{C}$ for $30 \mathrm{~s}, 55^{\circ} \mathrm{C}$ for $30 \mathrm{~s}$, and $72^{\circ} \mathrm{C}$ for $30 \mathrm{~s}$. PCR products were quantified and normalized to human beta 2-microglobulin (beta 2-m) mRNA levels determined in parallel assays for each sample (GFAT1-L / beta 2-m). The ratios for mean expression levels \pm S.D. in each tissue relative to skeletal muscle were shown. Assays were performed in duplicate and repeated four times.

\section{Cloning of full-length GFAT1-L cDNA}

A full-length GFAT1-L cDNA was PCR-amplified from human skeletal muscle QUICK-Clone cDNA (Clontech) using the primers TTTTTTTCATATGTGTGGTATATT TGCTTACTTAAACTAC and CCCTCGAGTTACTCT ACAGTCACAGATTTGGC. Reactions were carried out for 40 cycles under the following conditions: $95^{\circ} \mathrm{C}$ for $30 \mathrm{~s}$, $55^{\circ} \mathrm{C}$ for $30 \mathrm{~s}$, and $72^{\circ} \mathrm{C}$ for $2 \mathrm{~min}$, with a final extension at $72^{\circ} \mathrm{C}$ for $3 \mathrm{~min}$. The PCR product was isolated by $0.8 \%$ agarose gel electrophoresis, purified, inserted into the pT7Blue T-vector (Novagen, Madison, WI, USA), and sequenced.

Construction of Escherichia coli expression vectors for GFAT1 and GFAT1-L cDNAs

To increase expression levels of GFAT1 and GFAT1-L proteins in E. coli, we used PCR-based mutagenesis to in- troduce conservative mutations, converting E. coli lowusage codons to high-usage codons within the human GFAT1 and GFAT1-L gene sequences. Reverse transcription was performed using $2 \mu \mathrm{g}$ of human skeletal muscle mRNA, the primer P4 (CCCTCGAGTTACTCTACAGT CACAGATTTGGC), and M-MLV reverse transcriptase (Gibco BRL, Grand Island, NY) for $10 \mathrm{~min}$ at $37^{\circ} \mathrm{C}$ followed by a 5-min denaturation step. We performed PCR using the mutagenesis primer P1 GTTCCGCGTACTCGT CGTGAAATCCTGGAGACC (underlined nucleotides denote substitutions in the GFAT1 sequence), primer P4, and KOD dash polymerase (TOYOBO). The amplification was executed under the following conditions: preheated at $95^{\circ} \mathrm{C}$ for $1 \mathrm{~min}, 40$ cycles at $95^{\circ} \mathrm{C}$ for $30 \mathrm{~s}, 55^{\circ} \mathrm{C}$ for $30 \mathrm{~s}$, and $72^{\circ} \mathrm{C}$ for $45 \mathrm{~s}$, with a final extension at $72^{\circ} \mathrm{C}$ for $1 \mathrm{~min}$. A second PCR reaction was performed using $5 \mu \mathrm{l}$ of the above $\mathrm{PCR}$ product as template, the mutagenesis primer $\mathrm{P} 2$

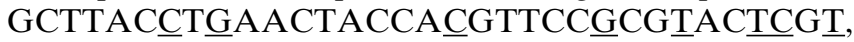
and primer $\mathrm{P} 4$ under the same conditions. Five microliters of the second PCR product was reamplified using the mutagenesis primer P3 TTTTTTTCATATGTGTGGTATCET TTGCTTACETGAACTAC and primer P4 under the same conditions. The final PCR product was analyzed by $0.8 \%$ agarose gel electrophoresis, purified, inserted into the pET23b vector (Novagen), and sequenced.

Expression and purification of recombinant GFAT1 and GFAT1-L

Vectors containing the full-length GFAT1 and GFAT1-L coding sequences, pET23/GFAT1 and pET23/GFAT1-L, were transformed into the $E$. coli strain BL21-Codon Plus (DE3)-RIL (Stratagene, La Jolla, CA, USA). Cultures were grown in Luria-Bertani medium containing $50 \mathrm{mg} / \mathrm{l}$ ampicillin at $30^{\circ} \mathrm{C}$ overnight. Fifty microliters of the culture was added to 11 of the fresh medium and incubated for $3 \mathrm{~h}$ at $37^{\circ} \mathrm{C}$ with vigorous agitation. Following the addition of $2 \mathrm{ml}$ of $1 \mathrm{M}$ isopropyl- $\beta$-D-thiogalactopyranoside (Wako Pure Chemicals Industries, Tokyo, Japan), cultures were incubated for $18 \mathrm{~h}$ at $20^{\circ} \mathrm{C}$ with vigorous agitation. Cells were harvested from 11 of culture by centrifugation, and the bacteria pellet was washed with cold Dulbecco's PBS (-) (Nissui Pharmaceutical, Tokyo, Japan). The cell pellet was the suspended in sonication buffer $(50 \mathrm{mM}$ sodium phosphate buffer [ $\mathrm{pH} 7.5]$ containing $20 \%$ [v/v] glycerol). After sonication, the lysate was centrifuged at $100,000 \mathrm{~g}$ for $30 \mathrm{~min}$ at $4^{\circ} \mathrm{C}$.

To concentrate the recombinant GFAT1 and GFAT1L proteins, we slowly added $100 \%$ saturated ammonium sulfate solution to the lysates to obtain $55 \%$ saturation. After centrifugation at $15,000 \mathrm{rpm}$ for $30 \mathrm{~min}$, the precipitates were dissolved in buffer $\mathrm{G}(50 \mathrm{mM}$ sodium phosphate buffer [pH7.5] containing $20 \%[\mathrm{v} / \mathrm{v}]$ glycerol and $1 \mathrm{mM}$ dithiothreitol) and desalted using a PD-10 gel filtration column (Amersham Pharmacia Biotech, UK). The concentrated sample solution was applied to a DEAESepharose column, which had been preequilibrated with buffer $\mathrm{G}$. The sample was eluted with buffer $\mathrm{G}$ containing 
$0.1 \mathrm{M} \mathrm{NaCl}$. Fractions containing recombinant GFAT1 were applied to a Sulfate-Cellulofine column that had been preequilibrated with buffer $\mathrm{G}$ containing $0.1 \mathrm{M} \mathrm{NaCl}$. Proteins were step eluted with buffer $\mathrm{G}$ containing $0.1 \mathrm{M}, 0.2 \mathrm{M}$, $0.3 \mathrm{M}, 0.4 \mathrm{M}$, and $0.5 \mathrm{M} \mathrm{NaCl}$. Fractions containing recombinant GFAT1-L were applied to a Heparin-Sepharose CL$6 \mathrm{~B}$ column that had been preequilibrated with buffer $\mathrm{G}$ containing $0.1 \mathrm{M} \mathrm{NaCl}$. Proteins were step eluted with buffer $\mathrm{G}$ containing $0.1 \mathrm{M}, 0.2 \mathrm{M}$, and $0.3 \mathrm{M} \mathrm{NaCl}$.

The sample was mixed with sodiumdodecyl sulfatepolyacrylamide gel electrophoresis (SDS-PAGE) sample buffer $(62.5 \mathrm{mM}$ Tris-HCl [pH6.8] containing 2\% [w/v] SDS, $7 \%$ [v/v] glycerol, $5 \%$ [v/v] 2-mercaptoethanol, and a trace of bromophenol blue) and boiled for $5 \mathrm{~min}$. Samples were fractionated on a $13 \%$ SDS polyacrylamide gel and stained with Coomassie Brilliant Blue R-250.

\section{Assays of enzyme activity}

GFAT activities were measured using a spectrophotometric assay, as described in Marshall et al. (1991). In a typical assay, $200 \mu \mathrm{l}$ of substrate buffer $(400 \mathrm{mM}$ sodium phosphate buffer [pH7.5], $50 \mathrm{mM} \mathrm{KCl}, 1.25 \mathrm{mM}$ ethylenediaminetetraacetate, $0.3 \mathrm{mM}$ 3-acetylpyridine adenine dinucleotide [APAD], 6U/ml glutamate dehydrogenase, $0-6 \mathrm{mM}$ fructose-6-phosphate [F6P]) was incubated with $50 \mu \mathrm{l}$ of diluted human GFAT1 or GFAT1-L recombinant protein for $60 \mathrm{~min}$ at $37^{\circ} \mathrm{C}$. The change in absorbance due to reduction of APAD to APADH was monitored spectrophotometrically at $365 \mathrm{~nm}$.

\section{Results and discussion}

\section{Expression profiles of $G F A T 1$}

To investigate the role of GFAT1 gene expression in insulin resistance, we examined expression profiles in human-tissue cDNA panels (Fig. 1). In the skeletal muscle cDNA library, we observed two distinct PCR products of $323 \mathrm{bp}$ and $377 \mathrm{bp}$. Sequence analysis identified the smaller product as the previously reported GFAT1 cDNA sequence (McKnight et al. 1992), whereas the larger product contained a novel 54-bp insertion between nucleotides 685 and 686 of the GFAT1 cDNA. We have designated this variant GFAT1-L. PCR products corresponding to GFAT1-L were detected in skeletal muscle and heart, with weak expression observed in brain. On the other hand, PCR products corresponding to GFAT1 were detected uniformly in all tissues.

To measure the relative levels of GFAT1-L mRNA in various tissue types, we performed quantitative PCR analysis (Fig. 2). Data were normalized to human beta 2-microglobulin mRNA levels. The highest levels of GFAT1-L expression were seen in skeletal muscle and heart, whereas low levels of expression were seen in brain. GFAT1-L expression in skeletal muscle was about 1.4 times higher than in heart and about 3.2 times higher than in

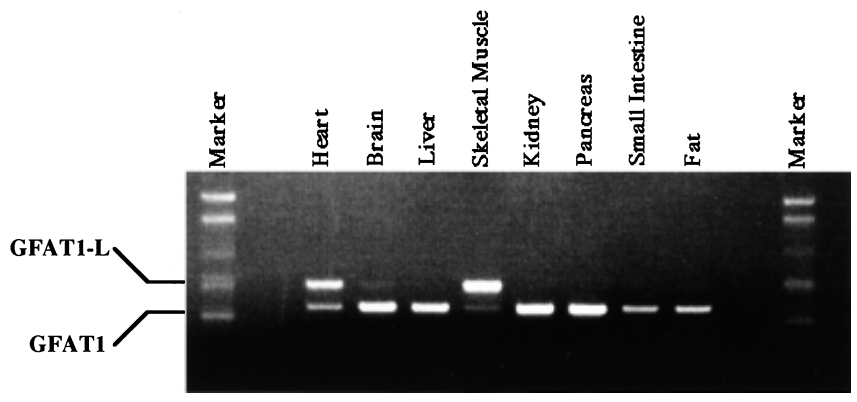

Fig. 1. Detection of two alternative splice transcripts, human GFAT1 and $G F A T 1-L$, by reverse transcriptase-polymerase chain reaction (RT-PCR). PCR was performed using QUICK-clone cDNA panels as templates. GFAT1- $L$ transcripts were identified in human heart, brain, and skeletal muscle

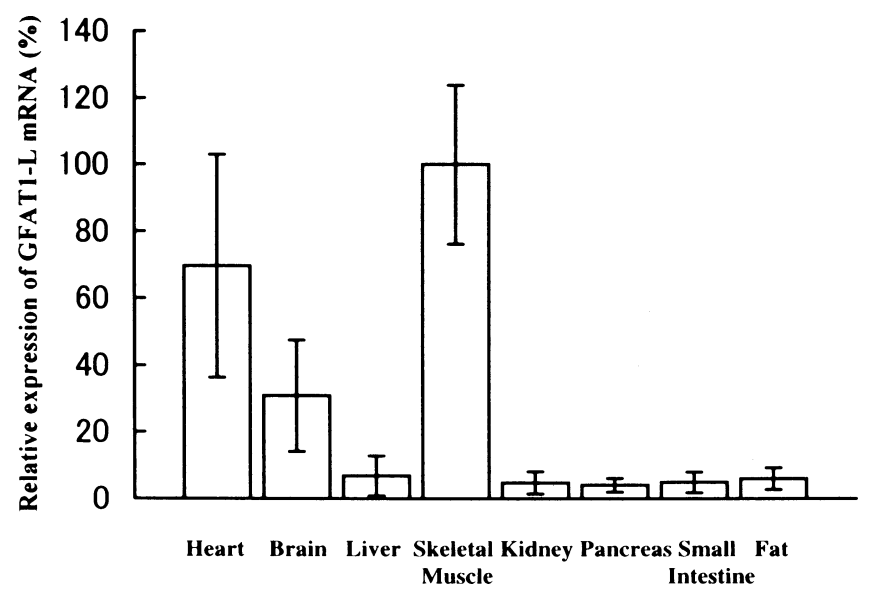

Fig. 2. Quantitative analysis of GFAT1- $L$ mRNA in tissues. SYBR Green I quantitative PCR methods were performed in duplicate and repeated four times. Levels of GFAT1-L mRNA amplification were normalized by comparison with human beta 2 -microglobulin mRNA. Results show the mean \pm S.D. expression levels relative to skeletal muscle

brain. In other tissues, only background levels of expression were observed. These findings suggest that expression of GFAT1-L is regulated in a tissue-specific manner.

Recently, the GFAT2 gene, which shares high homology with GFAT1, was isolated (Oki et al. 1999). Northern blot analysis showed differences in tissue distribution between GFAT1 and GFAT2. The highest levels of GFAT2 gene expression were observed in heart, placenta, and throughout the central nervous system. In contrast, GFAT1-L is expressed most abundantly in skeletal muscle, the most important tissue of insulin resistance in NIDDM (Rossetti et al. 1990; DeFronzo et al. 1985). In light of the known role of GFAT1 activation in insulin resistance, it is possible that GFAT1-L is also involved in the mechanism of skeletal muscle insulin resistance.

\section{Cloning of a novel GFAT1 splice variant}

To confirm the presence of complete transcripts coding for the putative $G F A T 1-L$ open reading frame, we isolated a 
Fig. 3.a,b Comparison of human GFAT1 and GFAT1-L sequences. a Schematic diagram of GFAT1 and GFAT1-L showing the GFAT1-L 54-bp insertion sequence. b Nucleotide and amino acid sequences of the hinge regions of human GFAT1 and GFAT1-L. Amino acid sequences of GFAT1 and GFAT1-L are indicated below and above the nucleotide sequences, respectively. Asterisks indicate nucleotide identity between GFAT1 and GFAT1-L. A putative protein kinase A phosphorylation site is boxed
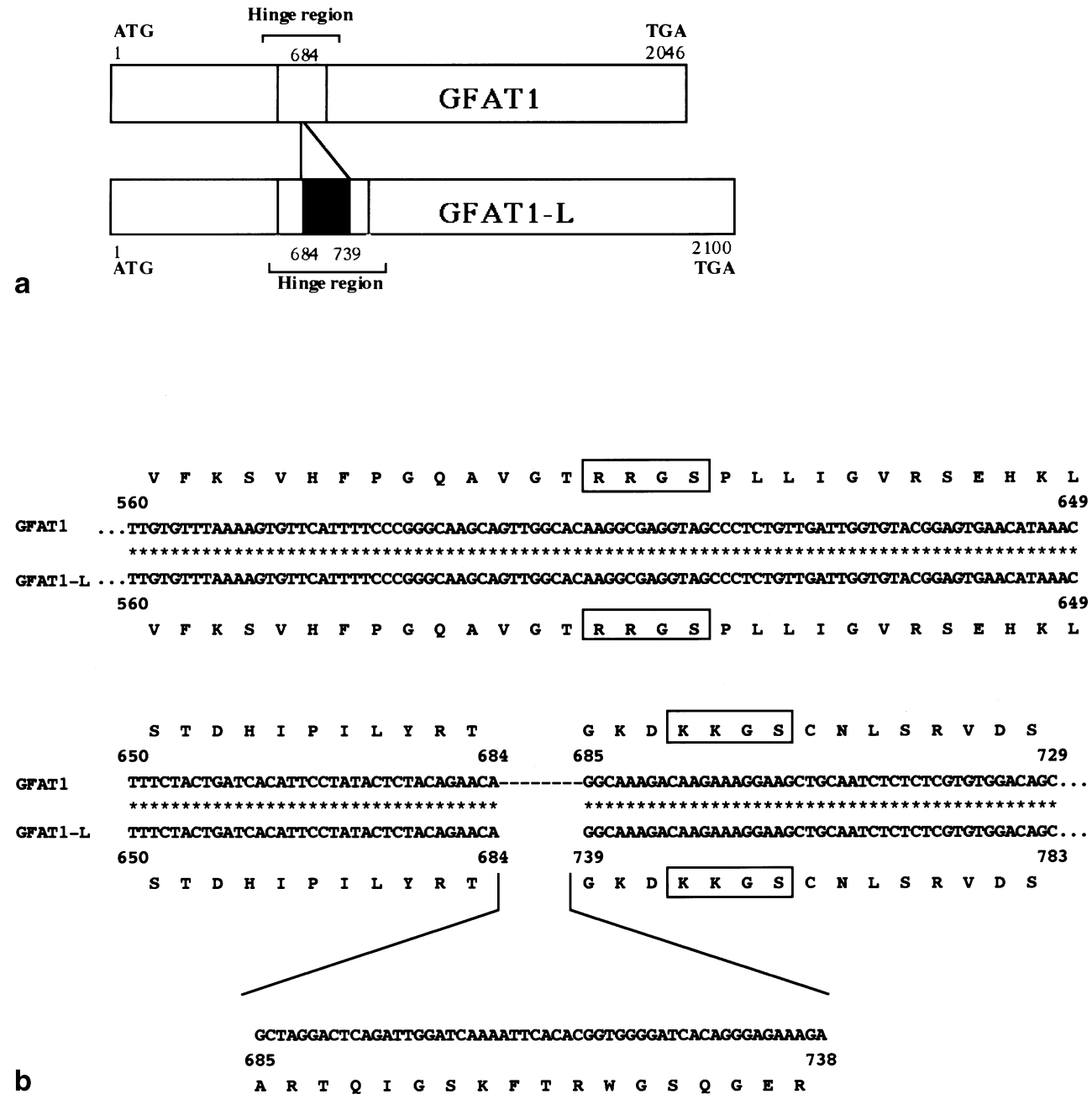

full-length cDNA clone from the human skeletal muscle cDNA library. DNA and amino acid sequences of GFAT1 and GFAT1-L, along with schematic representations of GFAT1 and GFAT-1L proteins, are presented in Fig. 3a,b. Aside from the insertion, the sequences of GFAT1 and GFAT1-L were identical. The GFAT1-L open reading frame consists of 2097 nucleotides, encoding a 699-aminoacid protein with a predicted molecular mass of $78790.38 \mathrm{Da}$ (GFAT1: 2043 bp, 681 amino acids, and 76743.22 Da). The GFAT1-L insertion occurs within a sequence corresponding to a hinge region in the GFAT1 protein (Zhou et al. 1998).

Expression of GFAT1 and GFAT1-L protein and GFAT activity assay

To produce recombinant GFAT1 and GFAT1-L proteins, we subcloned full-length cDNAs for these variants into E. coli expression vector pET23 vector and introduced them into E. coli strain BL21-Codon Plus (DE3)-RIL. As shown in Fig. 4, the approximately 77- and 79-kDa proteins were purified GFAT1 and GFAT1-L, respectively, which
Fig. 4. Expression of recombinant GFAT1 and GFAT1-L proteins. Lane 1, molecular weight standards; lane 2, GFAT1; lane 3, GFAT1-L. Proteins were solubilized in the sample buffer, and proteins were fractionated on a $13 \%$ sodium dodecyl sulfate polyacrylamide gel and stained with Coomassie Brilliant Blue R-250. Arrow at right denote recombinant GFAT1 and GFAT1-L proteins

predicted.

To determine if the GFAT1-L protein being expressed was functional, GFAT enzymatic activities were measured 


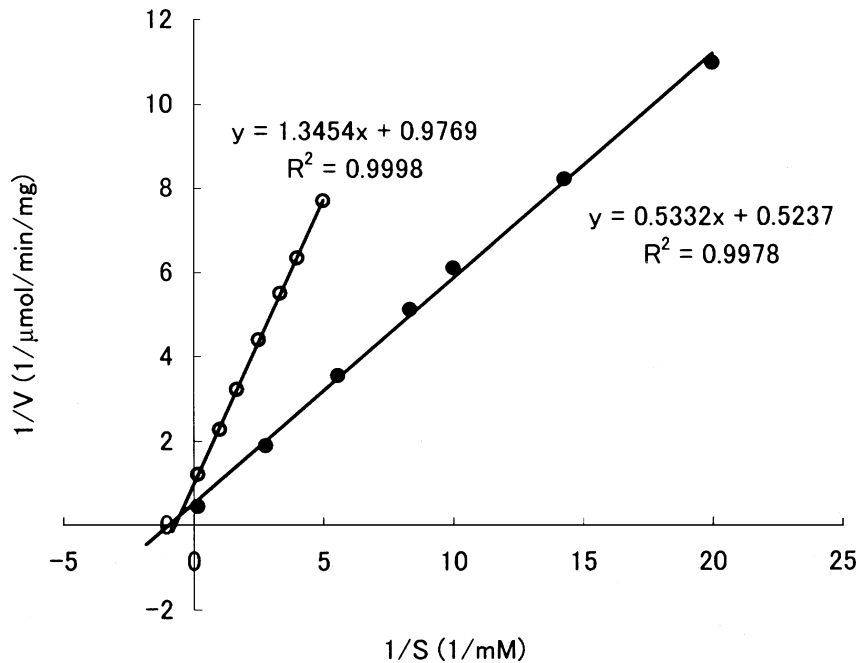

Fig. 5. Kinetic analysis of GFAT1 (solid circles) and GFAT1-L (open circles). GFAT enzyme activities were assayed at varying concentrations of fructose-6-phosphate. The reaction velocity was monitored spectrophotometrically $\left(\mathrm{A}_{365}\right)$. The dependence of the initial reaction velocity on substrate concentration was plotted in a linear fashion (Lineweaver-Burk plots). Each data point represents the mean of duplicate samples

(Fig. 5). As can be seen in Fig. 5, GFAT enzymatic activities were shown in recombinant GFAT1-L proteins to be the same as recombinant GFAT1 proteins. The $K m$ values of GFAT1 and GFAT1-L were derived from LineweaverBurk plots of activities using F6P as a substrate (Fig. 5). The $K m$ values of GFAT1 and GFAT1-L for F6P were calculated to be $1.02 \mathrm{mM}$ and $1.38 \mathrm{mM}$ respectively. Vmax values of GFAT1 and GFAT1-L for F6P were calculated to be $1.92 \mu \mathrm{mol} / \mathrm{min} / \mathrm{mg}$ and $1.02 \mu \mathrm{mol} / \mathrm{min} / \mathrm{mg}$, respectively. Some differences were shown in kinetic data between GFAT1 and GFAT1-L. The Vmax value showed two fold differences. Further investigation will be needed to understand whether these differences are significant in biochemical function.

We have described the identification of GFAT1-L, a novel splice variant of human GFAT1. GFAT1- $L$ contains a 54-bp insertion in the GFAT1 open reading frame, corresponding to an 18-amino-acid insertion in the predicted hinge region of the GFAT1 protein. Moreover, recombinant GFAT1-L proteins display functional GFAT enzymatic activities in vitro. These findings strongly suggest the existence of a functional variant of GFAT1 in vivo, previously considered to be a simplex enzyme. Also, the unique tissue distribution makes GFAT1-L a very interesting target for further research on the tissue-specific regulation of hexosamine generation and the potential link to insulin resistance.

Zhou et al. (1998) have shown that GFAT1 activity is regulated through phosphorylation by cAMP-dependent protein kinase A (PKA). Human GFAT1 contains two potential PKA phosphorylation sites. Using mass spectroscopy, Chang et al. (2000) recently mapped the PKA phosphorylation sites, demonstrating that GFAT1 is stoichiometrically phosphorylated at serine 205 and phospho- rylated to a lesser extent at serine 235 . This region, called the GFAT hinge region, is thought to be the regulatory element for GFAT activity. It is likely that the 18-aminoacid insertion into this hinge region in GFAT1-L results in altered substrate binding or phosphorylation. Further investigation is required to confirm the potential effects of this insertion on substrate binding or phosphorylation in vitro and in vivo.

It will be interesting to compare the contributions of GFAT1-L to skeletal muscle insulin resistance with the contributions of GFAT1, as defined by the studies of GFAT1 transgenic mice (Hebert et al. 1996; Cooksey et al. 1999) and GFAT1 overexpression in fibroblast cells (Crook et al. 1995, Crook et al. 2000). Also, immunostaining and in situ hybridization studies of GFAT should be revisited, as it will be possible to distinguish between GFAT1, GFAT1-L, and GFAT2. The identification of GFAT1-L has the potential to open new avenues of research into the mechanism of insulin resistance.

\section{References}

Baron AD, Zhu JS, Zhu JH, Weldon H, Maianu L, Garvey WT (1995) Glucosamine induces insulin resistance in vivo by affecting GLUT 4 translocation in skeletal muscle: implications for glucose toxicity. $\mathbf{J}$ Clin Invest 96:2792-2801

Buse MG, Robinson KA, Gettys TW, McMahon EG, Gulve EA (1997) Increased activity of the hexosamine synthesis pathway in muscles of insulin-resistant ob/ob mice. Am J Physiol 272:E1080-E1088

Chang Q, Baker JR, Yang X, Paterson AJ, Kudlow JE (2000) Phosphorylation of human glutamine:fructose-6-phosphate amidotransferase by cAMP dependent protein kinase at serine 205 blocks the enzyme activity. J Biol Chem 275:21981-21987

Chen H, Ing BL, Robinson KA, Feagin AC, Buse MG, Quon MJ (1997) Effects of overexpression of glutamine:fructose-6-phosphate amidotransferase (GFAT) and glucosamine treatment on translocation of GLUT4 in rat adipose cells. Mol Cell Endocrinol 135:67-77

Cooksey RC, Hebert LF Jr, Zhu JH, Wofford P, Garvey WT, McClain DA (1999) Mechanism of hexosamine-induced insulin resistance in transgenic mice overexpressing glutamine:fructose-6-phosphate amidotransferase: decreased glucose transporter GLUT4 translocation and reversal by treatment with thiazolidinedione. Endocrinology 140:1151-1157

Crook ED, Zhou J, Daniels M, Neidigh JL, McClain DA (1995) Regulation of glycogen synthase by glucose, glucosamine, and glutamine:fructose-6-phosphate amidotransferase. Diabetes 44:314320

Crook ED, Crenshaw G, Veerababu G, Singh LP (2000) Overexpression of glutamine:fructose-6-phosphate amidotransferase in rat-1 fibroblasts enhances glucose-mediated glycogen accumulation via suppression of glycogen phosphorylase activity. Endocrinology 141:1962-1970

Daniels MC, Ciaraldi TP, Nikoulina S, Henry RR, McClain DA (1996) Glutamine:fructose-6-phosphate amidotransferase activity in cultured human skeletal muscle cells: relationship to glucose disposal rate in control and non-insulin-dependent diabetes mellitus subjects and regulation by glucose and insulin. J Clin Invest 97:1235-1241

Davidson MB, Hunt K, Fernandez-Mejia C (1994) The hexosamine biosynthetic pathway and glucose-induced down regulation of glucose transport in L6 myotubes. Biochim Biophys Acta 1201:113-117

DeFronzo RA, Gunnarsson R, Bjorkman O, Olsson M, Wahren J (1985) Effects of insulin on peripheral and splanchnic glucose metabolism in noninsulin-dependent (type II) diabetes mellitus. J Clin Invest 76:149-155

Garvey WT, Olefsky JM, Matthaei S, Marshall S (1987) Glucose and insulin co-regulate the glucose transport system in primary cultured 
adipocytes: a new mechanism of insulin resistance. J Biol Chem 262:189-197

Hebert LF Jr, Daniels MC, Zhou J, Crook ED, Turner RL, Simmons ST, Neidigh JL, Zhu JS, Baron AD, McClain DA (1996) Overexpression of glutamine:fructose-6-phosphate amidotransferase in transgenic mice leads to insulin resistance. J Clin Invest 98:930936

Hiratsuka M, Agatsuma Y, Mizugaki M (1999) Rapid detection of CYP2C $9 * 3$ alleles by real-time fluorescence PCR based on SYBR Green. Mol Genet Metab 68:357-362

Marshall S, Bacote V, Traxinger RR (1991) Discovery of a metabolic pathway mediating glucose-induced desensitization of the glucose transport system: role of hexosamine biosynthesis in the induction of insulin resistance. J Biol Chem 266:4706-4712

McClain DA, Crook ED (1996) Hexosamines and insulin resistance. Diabetes 45:1003-1009

McKnight GL, Mudri SL, Mathewes SL, Traxinger RR, Marshall S, Sheppard PO, O'Hara PJ (1992) Molecular cloning, cDNA sequence, and bacterial expression of human glutamine:fructose-6phosphate amidotransferase. J Biol Chem 267:25208-25212

Morrison TB, Weis JJ, Wittwer CT (1998) Quantification of low-copy transcripts by continuous SYBR Green I monitoring during amplification. Biotechniques 24:954-958

Nerlich AG, Sauer U, Kolm-Litty V, Wagner E, Koch M, Schleicher ED (1998) Expression of glutamine:fructose-6-phosphate amidotransferase in human tissues: evidence for high variability and distinct regulation in diabetes. Diabetes 47:170-178

Oki T, Yamazaki K, Kuromitsu J, Okada M, Tanaka I (1999) cDNA cloning and mapping of a novel subtype of glutamine: fructose-6- phosphate amidotransferase (GFAT2) in human and mouse. Genomics 57:227-234

Rizza RA, Mandarino LJ, Gerich JE (1981) Mechanism and significance of insulin resistance in non-insulin-dependent diabetes mellitus. Diabetes 30:990-995

Robinson KA, Weinstein ML, Lindenmayer GE, Buse MG (1995) Effects of diabetes and hyperglycemia on the hexosamine synthesis pathway in rat muscle and liver. Diabetes 44:1438-1446

Rossetti L, Giaccari A, DeFronzo RA (1990) Glucose toxicity. Diabetes Care 13:610-630

Virkamaki A, Daniels MC, Hamalainen S, Utriainen T, McClain D, Yki-Jarvinen H (1997) Activation of the hexosamine pathway by glucosamine in vivo induces insulin resistance in multiple insulin sensitive tissues. Endocrinology 138:2501-2507

Wittwer CT, Herrmann MG, Moss AA, Rasmussen RP (1997) Continuous fluorescence monitoring of rapid cycle DNA amplification. Biotechniques 22:134-138

Yki-Jarvinen H, Daniels MC, Virkamaki A, Makimattila S, DeFronzo RA, McClain D (1996) Increased glutamine:fructose-6-phosphate amidotransferase activity in skeletal muscle of patients with NIDDM. Diabetes 45:302-307

Yki-Jarvinen H, Nyman T, Rissanen E, Leino M, Hamalainen S, Virkamaki A, Hauguel-de Mouzon S (1999) Glutamine: fructose-6phosphate amidotransferase activity and gene expression are regulated in a tissue-specific fashion in pregnant rats. Life Sci 65:215-223

Zhou J, Huynh QK, Hoffman RT, Crook ED, Daniels MC, Gulve EA, McClain DA (1998) Regulation of glutamine:fructose-6-phosphate amidotransferase by cAMP-dependent protein kinase. Diabetes 47:1836-1840 